\title{
Experiência Estética: Constituindo Professores de Arte
}

\section{Maria Cristna Aves dos Santos Pess:}

Este texto* refere-se a formação de professores de arte e às experiências estéticas vividas.

Experiência estética é aqui tratada nos termos da estética pragmatista de John Dewey.

$\mathrm{Na}$ escola, entre professores, assim como em outras profissões as ações são desenvolvidas por pessoas. Se pensarmos o professor de arte em unidade com a pessoa, o ser que é, estaremos nos aproximando do ideal de que algumas competências necessárias para orientar os processos artísticos e estéticos na educação escolar estão atrelados ao que é vivido.

Para este ser, que na área de atuação profissional possa ter escolhido a educação, tenho pensado a estética pragmatista de John Dewey (1859-1952), acreditando, pois é preciso acreditar, que ainda a arte no processo de educação escolar compreenda um espaço de encontro. Encontro do ser em sua totalidade, individual e social, sustentado por uma postura estética diante de suas ações.

Na estética pragmatista de Dewey encontrei fundamentos que solicitam ações em unidade e coerência com reflexões, um pragmatismo aliado à uma filosofia educacional que pede posturas conscientes do professor. A estética pragmatista de Dewey e sua filosofia educacional estão concentradas sobre o

* Parte integrante da Dissertação de Mestrado: PESSI, Maria Cristina A.S. Experiência estética: um percurso constitutivo de professora de arte, UDESC, 2001. 
conceito de experiência. As obras de Dewey apontam um sentido para experiência que a coloca como um todo vivido, experiência-vida, que une pensamento e atitude provocando experiências reflexivas. Estas experiências, por serem transformadoras, apresentamse como educativas, desta maneira a experiência estética tem caráter educativo e de formação humana. Percebo que, segundo Dewey, no campo da educação, a experiência é uma ação ativo-passiva e seu valor pode residir justamente nesta condição, na percepção das relações ou continuidades a que nos conduz. Viver uma experiência pode ser, para o professor assim como para o aluno, o impulso para uma atitude futura. Acredito que a qualidade de uma experiência possa estar contida no ato que ela, a experiência, nos impele a exercer.

Penso nos alunos orientados por professores que não tem clareza do seu papel na escola, que não tem consciência filosófica da finalidade do seu fazer, do seu compromisso com a vida de seus alunos e com a sua própria vida, pois sabemos que há inúmeros professores condicionados a esta situação imposta ao ser humano contemporâneo.

Para se compreender o sentido de experiência em Dewey e torná-lo um projeto realizável na educação escolar é preciso, primeiramente, entender e insistir em acreditar no ser humano como quem quer experienciar o mundo. É nesse experienciar o mundo, é nesse mundo vivido, é no olhar o movimento do mundo que o ser humano encontra as relações de sentido entre seus pensamentos e suas ações, tornando-se consciente. 0 ser consciente de si, do mundo, das relações, é capaz de construir uma 'práxis humana' que é "unidade indissolúvel entre minha ação e minha reflexão sobre o mundo"(Freire, 1980:26).

A prática docente requer uma reflexão constante sobre conteúdos, procedimentos, recursos, posturas do 
professor, requer também a superação de um viver a maior parte do tempo de modo inconsciente. As experiências reflexivas vividas, conforme as teorias deweyanas, levam a uma compreensão que possibilitam uma distinção do eu, que nos afastam de uma situação de mecanicidade, de respostas prontas, de certezas absolutas.

Pode-se afirmar que a pedagogia contemporânea vem sendo caracterizada pelo questionamento, pelas experiências reflexivas. Assim como Dewey ressaltou a necessidade de uma teoria da experiência para a educação progressista em contradição à educação tradicional, a contemporaneidade recuperou o significado de experiência para a arte na educação. A idéia de experiência se transformou atualmente num conceito bem apropriado para a arte na educação escolar. Quando Dewey apresentava seus ideais de educação progressista, como fez em seu Experiência e educação (1938) demonstrou conexão orgânica entre a educação e a experiência pessoal. Por sabermos que não se vive arte, na produção ou na apreciação, sem as pessoalidades confirma-se, assim, a necessidade de experiências cotidianas, reflexivas e estéticas para o desenvolvimento de processos de arte na educação escolar.

As experiências precisam ser vividas pelos alunos para que alcancem compreensão de si, do seu trabalho e da arte, bem como também considero-as fundamentais para a formação do professor. As experiências, para se realizarem como educativas, precisam, segundo Dewey (1971:17), se caracterizar como contínuas. Dewey trata que o 'continuum experiencial' auxilia a discriminar entre as experiências de valor educativo e as experiências sem tal valor. $O$ caráter de continuidade faz com que qualquer experiência tome algo das experiências passadas e modifique de algum modo experiências futuras, mas 
para isso é preciso que se processe dentro da pessoa em relação ao mundo. "A experiência somente é verdadeiramente experiência, quando as condições se acham subordinadas ao que ocorre dentro dos indivíduos que passam pela experiência"(Dewey,1971:33). Esta afirmação demonstra, além do princípio de continuidade, o princípio de interação da experiência. Continuidade e interação se interceptam e se unem, alcançando os rumos da educação e da arte na educação escolar.

O sentido de vivenciar, de apropriação com a consciência, de interação, faz a arte em produção ou contemplação mexer com a existência de quem a produz ou contempla, professor ou aluno. A ação e movimento que a filosofia pragmatista de Dewey enfatiza no processo educacional e estético é pensada com o sentido de tornar o ser humano consciente. Próximo deste sentido de 'mexer com a existência' ou de 'ação e movimento' está Maturana (1997:212) ao dizer que a experiência que conotamos como consciente é uma experiência de autodistinção, "quando nós distinguimos a nós mesmos fazendo distinções", sendo uma experiência especial e contundente que torna o corpo consciente diante das dinâmicas e relações do viver. $E$, embora a consciência não esteja localizada no sistema nervoso, em alguma parte específica ou no corpo do ser humano em geral, ela se manifesta em sua corporalidade alterando suas ações. Desta forma, pode-se considerar as experiências reflexivas, conscientes, estéticas como educativas e de formação profissional.

Aqueles que vivem momentos de contemplação, que vivem experiências estéticas se modificam neste processo, isto significa, entre outras coisas o 
reconhecimento de incompletudes, de equívocos e solicita a coragem para realizar mudanças e para se envolver em novas aprendizagens. Em vista disto, penso que os professores de arte seriam, por lidarem em seu cotidiano com conhecimento e experiências em arte, os profissionais que estariam especialmente em transformação, constantemente em processos de reflexão sobre si e sobre suas escolhas.

Dufrene afirmou que ao empreender o estudo da experiência estética faz-se justiça ao ser humano: de um lado, o gesto criador, de outro, a recepção da obra, sua interpretação e sua apreciação. "Se o homem na experiência estética, não realiza necessariamente sua vocação, ao menos manifesta melhor sua condição: essa experiência revela sua relação mais profunda e mais estreita com o mundo" (Dufrene, 1981:25). Sobre um sentido para experiência estética, continua:

(...) O sentido só pode aparecer nessa experiência se todas as potências da consciência nela já estão presentes. A percepção estética é a percepção aberta e feliz que atesta essas potências e solicita a reflexão sobre elas. Ao mesmo tempo, ela anuncia e prepara para a consciência o seu futuro, fundamenta-o,(..)a experiência estética reconcilia-nos conosco mesmo(...) (idem,p.26).

E ainda, "a experiência estética se situa na origem, naquele ponto em que o homem, confundido inteiramente com as coisas, experimenta sua familiaridade com o mundo" (Dufrene, 1981:31).

As relações 'mais profundas' e 'mais estreitas' com o mundo, quando o experimentamos em 'familiaridade', correspondem ao sentido de envolvimento e unidade expresso na estética pragmatista de Dewey. Correspondem, também, à encontros que desencadeiam experiências reflexivas e estéticas. 
Uma metáfora, 'a pedra que rola', se apropria bem para tratar de formação humana, formação profissional e desenvolver a relação entre as experiências estéticas vivenciadas pelos professores e seus processos escolares em arte. Dewey em Art as experience descreve este exemplo:

(...) se imaginarmos uma pedra, a qual esteja rolando por uma colina, para ter uma experiência. Sua atividade é seguramente 'prática'. A pedra parte de algum lugar, e movimenta-se, conforme o permitam as condições, para um lugar e para um estado onde possa permanecer imóvel - para um fim. Agreguemos, pela imaginação, a tais fatos externos, as idéias de que a pedra olha para diante desejando o resultado final; que se interessa pelas coisas que encontra pelo caminho, condições que acelerame retardam seu movimento em relação a seu término; que atua e sente com respeito a elas de acordo com a função de impulsioná-la ou detê-la que lhes atribua; e que a chegada final ao repouso seja relacionada com tudo o que aconteceu antes enquanto a culminância de um movimento contínuo. Então a pedra teria uma experiência, e dotada de qualidade estética (1989:46).

Continuidade e interação, princípios deweyanos de experiência, estão expressos neste exemplo, assim como são condições de existência humana. A pedra, ao rolar, cursa uma trajetória e vai de um lugar a outro, ação eminentemente prática; mas, não apenas vai de um lugar a outro, transforma-se neste percurso. A pedra ao rolar a colina encontra diferentes texturas no solo, alguns lugares por onde passa podem ser úmidos ou sombrios, outros podem ser secos, ensolarados, aconchegantes ou repulsivos. Outras pedras, vegetação ou pequenos animais podem se apresentar no caminho. Em interação e continuidade 'tudo' repercute na pedra em si e no percurso. A ação prática do deslocamento, para não ser simplesmente mecânica, precisa ser mesclada por uma intenção (ação) reflexiva. 
Constituir-se humano, profissional, professor, exige um compromisso pessoal com atitudes reflexivas. As experiências com qualidade estética contribuem para a formação reflexiva de professores. Nóvoa afirma que

(...) pela formação reflexiva de professores passa uma parte significativa das apostas de mudança educacional, de melhoria da qualidade do ensino e de desenvolvimento de práticas educativas (pedagógicas, organizacionais e institucionais) que contribuem para uma maior igualdade e justiça social (Zeichner, 1993:12).

Assim, a abrangência de experiências estéticas, conscientes e reflexivas alcançam 'o universo no qual vivemos'. Universo entendido como 'ser um todo', a unidade entre integridade humana e docente, ou 'pertencer a um todo', o meio social, terrestre, cósmico' ${ }^{1}$.

Partindo de uma experiência pessoal, é possível o deslocamento para o contexto mais amplo da sociedade. Penso que a experiência estética não será apenas constituinte do ser, do professor, mas, através deste em sua ação educativa, poderá ser também parte essencial da vida social ${ }^{2}$.

1. Cfme. Edgar Morin, Os sete saberes necessários à educação do futuro, p.51.

"Somos originários do cosmos, da natureza, da vida, mas devido à própria humanidade, à nossa cultura, à nossa mente, à nossa consciência, tornamo-nos estranhos a este cosmos, que nos parece secretamente íntimo. Nosso pensamento e nossa consciência fazem-nos conhecer o mundo físico e distanciamnos dele. O próprio fato de considerar racional e cientificamente o universo separa-nos dele. Desenvolvemo-nos além do mundo físico e vivo. É neste 'além' que tem lugar a plenitude da humanidade."

2. Cfme. Roger Bastide, Arte e sociedade,p.3.

"(...) a arte não é um simples jogo individual sem conseqüência, mas pelo contrário, agindo sobre a vida coletiva, pode transformar o destino das sociedades. Mas este é apenas um dos aspectos da questâo, pois deve-se examinar igualmente se a recíproca não é verdadeira, se a arte não é também um produto da vida coletiva e se o seu destino não está em função do destino das sociedades." 
Por acreditar que as experiências estéticas vividas pelos professores conduzem a reflexões existenciais e profissionais, e orientada pela postura de Dewey, quando propõe em seu pragmatismo, unidade entre reflexão e ação, considero, também, experiência estética como essencial para o processo pessoal de fazer-se professor de arte. É possível também aproximar o enfoque pragmatista de Dewey ao enfoque fenomenológico de Merleau-Ponty, pois não somos consciência reflexiva pura, somos uma consciência corporificada ou uma 'consciência encarnada num corpo' (Merleau-Ponty,1978:279). A experiência estética ao tornar o professor, o ser, modificado pela contemplação, mudança esta percebida pelas ações, permite "(...) reencontraro corpo operante e atual, aquele que não é um pedaço de espaço, um feixe de funções, mas um entrelaçado de visão e de movimento "(Merleau-Ponty,1978:278). Dufrene confirma: " $E$ preciso dar sentido à experiência para que seja estética, (...) um sentido que ressoa no mais profundo do corpo (1981:25). Estas aproximações nos levam ao entendimento de unidade, conforme Dewey também afirmou, entre 'corpo' e 'espírito', 'trabalho' e 'existência', 'pessoa' e 'profissional', 'ser' e 'ensinar'.

Criar-se, constituir-se, transformar-se, este é o sentido de autopoiésis que a experiência estética provoca. Dewey confirma quando, ao tratar as emoções como qualidade que caracteriza a unidade em uma experiência, oferecendo caráter estético, cita-a como o que "move e muda" (1989:48).

Autopoiesis, a criação de si, é um termo que vem sendo empregado por Maturana em sua obra para, como biólogo, explicar a vida (Bauer:1998). Poiesis é criação, e dá sentido a vida em seu movimento. A vida, em sua unidade ou destacando o caráter de formação 
docente, é poiética em seu sentido clássico ${ }^{3}$. Nas invenções e reinvenções da vida, os seres criam seu mundo exterior e interior, e este mundo é renovado a partir daquilo que o ser é. Assim, pode-se pensar que nós professores nos fazemos em nossa prática, sem dicotomia entre trabalho e existência.

A maneira como cada um de nós ensina está diretamente dependente daquilo que somos como pessoa quando exercemos o ensino: 'Será que a educação do educador não se deve fazer mais pelo conhecimento de si próprio do que pelo conhecimento da disciplina que ensina?' (Laborit, 1992:55) Eis-nos de novo face à 'pessoa' e ao 'profissional', ao 'ser' e ao 'ensinar'. Aqui estamos. Nós e a profissão. Eas opções que cada um de nós tem de fazer como professor, as quais cruzam a nossa maneira de ser com a nossa maneira de ensinar e desvendam na nossa maneira de ensinar a nossa maneira de ser. É impossível separar o 'eu' profissional do 'eu' pessoal (Nóvoa, 1992:17).

Unidas em sua origem, a experiência estética (aisthesis) e a criação ${ }^{4}$ (poiesis) fazem com que o

3. Poiético, in: Nicola Abbagnano, Dicionário de Filosofia, referese a "produtivo ou criativo, enquanto diferente de 'prático'. Segundo Aristóteles, a arte é produtiva, enquanto a ação não é." (p.772); "(...) para Aristóteles a arte pertence ao domínio prático e constitui o objeto da 'poética', ou seja, da ciência da produção, enquanto a outra subdivisão da prática é a ciência da ação."(p.372)

Cfme. Marilena Chaui, Convite à filosofia, p.321, temos que:

"Do ponto de vista da Filosofia podemos falar em dois grandes momentos de teorização da arte. No primeiro, inaugurado por Platão e Aristóteles, a Filosofia trata as artes sob a forma da 'poética'; no segundo, a partir do século XVIII, sob a forma da 'estética'. "Arte poética' é o nome de uma obra aristotélica sobre as artes da fala e da escrita, do canto e da dança: poesia e teatro (tragédia e comédia). A palavra 'poética' é a tradução para 'poiesis'."

4. Neste caso refiro-me especificamente a 'criaçăo de si', entretanto não desconheço que, cfme.Hans Robert Jauss, $A$ literatura e o leitor, p.78-82:

"As funções produtiva e receptiva da experiência estética desenvolvem-se sob três conceitos da tradição estética: poiesis, aisthesis e katharsis. Designamos por poiesis, compreendida no 
professor, com sabor ${ }^{5}$ e prazer, renove seu mundo, inove seus processos pedagógicos, descubra um aprender contínuo. A experiência estética promove a autoconsciência, e esta sustenta o processo reflexivo do professor em sua existência.

Entre as reflexões sobre experiência estética apresentadas neste artigo permito-me destacar a profundidade do pensamento deweyano em escrever

sentido aristotélico da 'faculdade poética', o prazer ante a obra que nós mesmos realizamos... Como afirmação estética produtiva fundamental, a 'poiesis' corresponde à caracterização de Hegel sobre à arte, segundo a qual o indivíduo, pela criação artística, pode satisfazer a sua necessidade geral de 'sentir-se em casa no mundo', ao 'retirar do mundo exterior a sua dura estranheza' $e$ convertê-la em sua própria obra'.(...) Aisthesis designa o prazer estético da percepção, é experiência estética receptiva básica,(...) a aisthesis corresponde assim a determinações diversas da arte: como 'pura visibilidade' (Konrad Fiedler), que compreende a recepção prazeirosa do objeto estético como uma visão intensificada, sem conceito ou, através do processo de estranhamento (Chklovski), como uma visão renovada; como 'contemplação desinteressada da plenitude do objeto' (Moritz Geiger); como experiência da 'densidade do ser' (J. P. Sartre); em suma, como 'pregnância perceptiva complexa' (Dieter Henrich). Legitima-se desta maneira, o conhecimento sensivel, face à primazia do conhecimento conceitual. Designa-se por katharsis, (...) aquele prazer dos afetos provocados pelo discurso ou pela poesia, capaz de conduzir o ouvinte e o expectador tanto à transformação de suas convicções, quanto à liberação de sua psique. (...)A própria atividade da aisthesis, contudo, também pode se converter em poiesis. (grifo meu)O observador pode considerar o objeto estético como incompleto, sair de sua atitude contemplativa e converter-se em co-criador da obra, à medida que conclui a concretização de sua forma e de seu significado. A experiência da aisthesis pode, por fim se incluir no processo de uma formação estética da identidade, quando o leitor faz a sua atividade estética ser acompanhada pela reflexão sobre seu próprio devir: (grifo meu). "A importância do texto não advém da autoridade de seu autor, não importa como ela se legitime, mas sim da confrontaçāo com a nossa biografia. O autor somos nós, pois cada um é o autor de sua biografia" (Zimmermann apud

5. Lembro Roland Barthes, A aula,1999.

"Sapientia: nenhum poder, um pouco de saber, um pouco de sabedoria, e o máximo de sabor possível." 
que a vida humana orienta-se por um desejo de experimentar o mundo e dar significado a tudo. A arte, segundo Dewey, dá possibilidades para que estas necessidades sejam atendidas, permitindo ao ser humano crescer consciente e superar as fendas do mundo.

\section{Referências Bibliográficas}

ALEXANDER, Thomas. The art of life: Dewey's aesthetics. In: HICKMAN, Larry.

Reading Dewey: interpretations for a postmodern generation. Bloomington and

Indianapolis: Indiana Universiity Press, 1998, p.01-22.

BARBOSA, Ana Mae. Recorte e colagem: influências de John Dewey no ensino da arte no

Brasil. São Paulo: Cortez, 1982.

BARTHES, Roland. Aula. São Paulo: Cultrix, s/d.

BAUER, Ruben. Gestão da mudança: caos e complexidade nas organizações. São Paulo:

Atlas, 1998, cap. 7, Autopoiesis: a ordem que decorre de ser.

DEWEY, John. John Dewey, the later works:1925 - 1953, volume 10: 1934, Art as experience. Carbondale: Soouthern Illinois University Press, 1989.

- Vida e educação. Rio de Janeiro:

Melhoramentos, 1978.

- Experiência e educação. São Paulo: Companhia Editora Nacional, 1971.

- Democracia e educação. São Paulo: Companhia Editora Nacional, 1959.

. Como pensamos. São Paulo: Companhia Editora Nacional, 1933.

. Experiência e natureza. São Paulo: Abril, 1974.

Coleção Os Pensadores.

DUFRENE, Mikel. Estética e filosofia. São Paulo:

Perspectiva, 1981, $2^{\mathrm{a}}$ ed.

FREIRE, Paulo. Conscientização. São Paulo: Moraes, 1980 
HICKMAN, Larry A. The Essential Dewey. Anais do I Congresso Latino de Filosofia da Educação, Rio de Janeiro: Associação Brasileira de Educação,2000.

MATURANA, Humberto. A ontologia da realidade. Belo Horizonte: Ed. UFMG, 1997.

MERLEAU-PONTY, Maurice. O olho e o espírito. São Paulo: Nova Cultural, 1980.

MORIN, Edgar. Os sete saberes necessários à educação do futuro. São Paulo: Cortez, 2002.

NÒVOA, António. Vidas de professores. Portugal: Porto Editora, 1992.

- Os professores e sua formação. Lisboa:

DomQuixote, 1992

. Profissão professor. Portugal: Porto Editora, 1995, $2^{a}$ ed.

ZEICHNER, Kenneth M. A formação reflexiva de professores: idéias e práticas. Lisboa: Educa,1993. 